\title{
AS QUATRO ADAPTAÇÕES RECENTES DE $O$ ALIENISTA, DE MACHADO DE ASSIS EM QUADRINHOS
}

\author{
Bárbara Cristina Almada da Silva (UNESA) \\ barbaraalmada@bol.com.br \\ Nataniel dos Santos Gomes (UNESA) \\ natanielgomes@hotmail.com
}

\section{Arquitetura da Nona Arte}

Desde os tempos das cavernas os homens utilizavam desenhos para retratar suas aventuras. Deixavam marcados em pedras seus desenhos que possuíam uma sequência visual permitindo a leitura concreta dos fatos, pois a disposição dos desenhos era sequencial, assim como as histórias em quadrinhos na atualidade. (LANNONE E LANNONE, 1998, p. 11)

O que chamamos de história em quadrinhos na atualidade surgiu no século passado, e não possuía a forma que possui hoje. Ela era, na maioria das vezes, representada por um único quadro, seu texto era em prosa ou verso e o diálogo era praticamente insistente. Alguns artistas construíam as histórias em quadros sequenciais, sem diálogo explorando bastante o cenário visual que possuía grande riqueza de detalhes

De acordo com Lannone e Lannone (1998, p. 21) o primeiro personagem dos quadrinhos foi um menino com feições orientais que se chamava Yellow Kid (Figura 1), criado pelo artista norte-americano Richard Outcault, em 1895. Este personagem se comunicava através de frases escritas em um camisolão amarelo que ele usava. Com o passar dos tempos o personagem evoluiu e suas falas passaram a ser transcritas dentro de balões, surge então o primeiro balão de pensamento o que deu origem através da evolução às grandes historias em quadrinhos da atualidade, que utilizam balões para representar a fala e o pensamento de seus personagens. 


\section{FACULDADE DE FORMAÇÃO dE PROFESSORES}

O Yellow Kid tem origem nos Estados Unidos logo seus textos são escritos em inglês, sua primeira edição foi em 1896 no New York Journal American. Seu autor foi Richard Felton Outcault e seu gênero era caracterizado como humor.

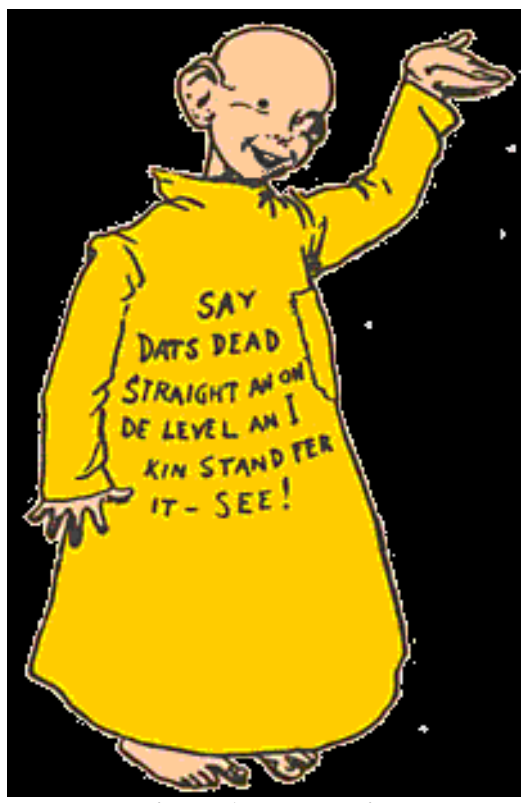

Figura 1: Yellow Kid

Com o passar dos tempos os quadrinhos foram se concretizando e se tomando uma espécie de cultura de massa, principalmente depois do surgimento dos super-heróis que conquistaram o publico juvenil. Suas relevâncias eram tão significantes que passou a ter um espaço exclusivo nos jornais com publicações semanais. O público de leitores dos jornais esperava com tanta ansiedade os quadrinhos que logo passaram a ter mais importância do que as próprias notícias, o que incomodou profundamente a imprensa e os intelectuais que iniciaram uma guerra velada contra a Nona Arte. (FEIJOR, 1995, p. 39)

A influência dos personagens dos quadrinhos era tamanha que motivou o então nomeado Chanceler da Alemanha, Adolf Hitler em seu Terceiro Reich, a usar o personagem Super-Homem (Figura 2) para introjetar na mente dos jovens os princípios nazista, uma vez que todos seus adeptos seriam também classificados como super-homens. 
Goebbels, ministro da cultura popular e da propaganda do ditador Adolf Hitler (1889-1945), imediatamente enxergou no kriptoniano um perigoso inimigo para a propaganda alemã.

O Super-Homem era a negação dos ideais nazistas. Mesmo sendo um ser superior aos humanos, ele era pacifista e representava o ideal dos fortes protegendo os mais fracos e servindo-lhes sem dominá-los. A propaganda nazista ao contrário explorava o mito do Super-Homem para justificar que os mais fortes tudo podiam e que deveriam dominar os fracos e covardes. (FEIJOR, 1995).

Infelizmente, a arte sequencial sempre esteve associada a ideia de comunicação com o publico dito inculto,as elites da época trataram logo de condenar os quadrinhos inclusive negando-lhes o status de arte. (LANNONE E LANNONE, 1995, p. 20)

Diante de todo este preconceito no início dos anos cinquenta nos Estados Unidos, o psicólogo Frederick Werthan escreve o livro intitulado A sedução dos Inocentes que aponta os quadrinhos como responsáveis pela delinquência juvenil.

Apesar de todos os esforços para propagar o lado pedagógico, intelectual e artístico dos quadrinhos por parte de vários estudiosos, talvez poucos (ou nenhum) tenham explorado o mundo das HQs quanto esta obra, que Frederic Wertham escreveu em 1954. O livro foi lançado nos Estados Unidos e levantou a hipótese de que os quadrinhos da época influenciavam os jovens a cometerem atitudes delinquentes e imorais. Foi nesse livro que Wertham sugeriu que Batman e Robin constituíam um casal homossexual e que a Mulher-Maravilha era lésbica. Essas suspeitas foram levadas tão a sério que vários pais fizeram fogueiras com gibis e até um grupo chamado Comics (cômicos) chamado Comics Code foi criado para definir parâmetros "éticos" para os quadrinhos (na prática, uma censura). Este foi o ponto de partida para uma série de críticas negativas que se perdura até os tempos atuais em relação à Nona Arte. Disponível em: < http://super.abril.com.br/superarquivo/2004/conteudo_124555.shtm > . Acesso em: 15/05/2011 às 10:00h).

$\mathrm{Na}$ atualidade, os quadrinhos vem se desenvolvendo cada dia mais e várias técnicas novas estão surgindo conquistando a admiração de um publico cada vez maior, o que era historinha para crianças hoje conquista cada vez mais o público adulto.

Veremos abaixo os diferentes recursos utilizados nas HQs. 


\subsection{Os diferentes tipos de quadrinhos e seus artifícios}

A Nona Arte pode ser representada de varias formas estética:

- A palavra gibi nomeou a marca de revistas em quadrinho. Seu nome significa menino negrinho, em banto, como todo produto de sucesso seu nome rotula uma série de outros produtos do mesmo gênero criado posteriormente, assim o que lemos hoje não é Gibi e sim revistas em quadrinhos, doravante HQs.

- Charge é um estilo de ilustração que tem por finalidade satirizar, por meio de uma caricatura, algum acontecimento atual com uma ou mais personagens envolvidas. A palavra é de origem francesa e significa car$g a$, ou seja, exagera traços do caráter de alguém ou de algo para lhe dar um teor satírico.

- Um cartoon, cartune ou cartum é um desenho humorístico acompanhado ou não de legenda, de caráter extremamente crítico retratando de forma bastante sintetizada algo que envolve o dia-a-dia de uma sociedade.

- A tirinha, também conhecida como tira diária, é uma sequência de imagens. O termo é atualmente mais usado para definir as tiras curtas publicadas em jornais, mas historicamente o termo foi designado para definir qualquer espécie de tira, não havendo limite máximo de quadros tendo, claro, o mínimo de dois.

- A revista em quadrinhos, como é chamada no Brasil, ou comic book como é predominantemente conhecida nos Estados Unidos, é o formato comumente usado para a publicação de histórias do gênero, desde séries românticas aos populares super-heróis.

- Grafic Novel é o termo geralmente usado para referir-se a qualquer forma de quadrinho de longa duração, é o análogo na arte sequencial. Pode ser aplicado a trabalhos que foram publicados anteriormente em quadrinhos periódicos, ou a trabalhos produzidos especificamente para publicação em formato livro. Uma graphic novel não precisa ser voltada para o público adulto; às vezes, é necessário apenas que tenha uma boa estrutura e um visível grau filosófico. Disponível em: <http://super.abril.com.br/superarquivo/2004/conteudo_124555.shtm> . Acesso em: 20/05/2011, às 00:34h) 


\subsection{Recursos importantes para usar em sala de aula}

Como os quadrinhos dispõem de recursos visuais, alguns elementos se tornam muito importante para leitor identificar aspectos primordiais da historia. Vamos analisá-los a seguir:

\subsubsection{Cores}

As cores são elementos importantes na comunicação visual e, portanto, nos quadrinhos, grande parte das informações são transmitidas pelo seu uso. A cor é um elemento que compõe a linguagem dos quadrinhos; mesmo nas histórias em preto e branco, não se trata apenas de um recurso estilístico. Os desenhistas americanos perceberam a importância das cores e passaram a não restringir o uso de cores apenas ao cenário, elas assumiram a capacidade de simbolizar determinados elementos, principalmente nos quadrinhos norte-americanos de massa, passando a simbolizar personagens na mente do leitor. O Incrível Hulk é verde, originalmente cinza, mas a impressão não ficou boa e ele foi transformado em verde a partir da segunda edição. O Lanterna Verde também é verde. O Capitão-América tem o uniforme com as cores da bandeira norteamericana. Os duendes alemãs Smurfs são conhecidos por serem todos azuis. No Brasil, Maurício de Souza também utilizou as cores para criar as identidades de seus personagens. Uma menina forte como a Mônica só poderia usar um vestido vermelho; que menino travesso não desejaria dar um nó nas orelhas de um objeto tão particular quanto um coelho de pelúcia azul?

O conhecimento das sensações e reações provocadas pelas cores é um importante instrumento de comunicação que tem sido usado nas HQs. Sabemos que o rosa, por exemplo, é uma cor feminina e juvenil, assim como o violeta. $\mathrm{O}$ vermelho evoca força, energia e está associado à vida, por ser a cor do sangue. Também se usa o vermelho para caracterizar situações de perigo, assim como nos sinais de trânsito e etc. (Wikipédia, $15 / 05 / 2011$ às 12:30h.)

\subsubsection{Balões}

Os balões são recursos gráficos utilizados para tornar sons e falas visíveis na literatura. $\mathrm{O}$ balão seria o recurso gráfico representativo da fala ou do pensamento, que procura indicar um pensamento, um monólogo 


\section{FACULDADE DE FORMAÇÃO DE PROFESSORES}

ou um diálogo. Os quadrinhos necessitam do balão para a visualização das palavras ditas pelas personagens. Diferentemente da literatura, mesmo a ilustrada, os quadrinhos não precisam indicar ao leitor a qual personagem corresponde aquela fala ou pensamento, pois os balões indicam por meio do apêndice.

$\mathrm{O}$ formato dos balões pode variar de acordo com as intenções do autor. $\mathrm{O}$ balão de fala tem um contorno forte, nítido; o balão de pensamento tem outra forma. Ele é irregular, ondulado ou quebrado e o apêndice (biquinho que direciona de qual personagem é a fala ou o pensamento) tem o formato de pequenos círculos. Pensar é algo bem diferente de falar em voz alta, ainda que seja um monólogo, por isso existe essa distinção entre os balões. O contorno do balão pode ser tremido, indicando medo ou emoção forte, pode ser recortado, o que indica explosão verbal ou raiva, ou mesmo pontiagudo, fazendo o leitor perceber que o som está sendo emitido por uma máquina. Também podem ser usados alguns contornos metafóricos, como estalactites (que indicam frieza na resposta) ou pequenas flores (que indicam o oposto). Outra característica dos balões é ajudar a mostrar ao leitor a ordem de leitura e a passagem do tempo. Uma exigência fundamental é que sejam lidos numa sequência determinada, para que se saiba quem fala primeiro. Uma boa prática pedagógica é incentivar os alunos a descobrir vários tipos de balões e a criar os seus próprios.

\subsubsection{Lapso de tempo}

O lapso de tempo é o espaço que liga o quadro anterior ao posterior. Deve ser completado pela imaginação do leitor, fazendo com que a história tenha sequência. Para entender o quadrinho, é preciso entender o que aconteceu antes e o que acontecerá depois. Isoladamente, um quadrinho que faz parte de uma história é difícil de entender, mas duas imagens constituem uma narrativa, desde que sejam colocadas em sucessão e que o leitor as entenda assim. Nas histórias em quadrinhos o leitor constrói e confirma a narrativa que faz sentido na história. O lapso de tempo aceitável está no meio de duas imagens que representam continuidade. As transições são possíveis porque o leitor está acostumado a ler o corpo do texto como narrativa. O leitor procura, então, juntar os quadros para formar linearidade. Esta busca para "fechar" a narrativa, ou para "completá-la" estimula a criatividade e faz das HQs importantes instrumentos para a formação de leitores. 


\subsubsection{Metáforas visuais}

As metáforas visuais são usadas pelos autores para transmitir situações da história por meio de imagens, sem utilização do texto verbal. Quando o personagem está nervoso, de sua cabeça sai fumaça. Quando alguém está correndo muito rápido, aparecem vários traços paralelos e uma nuvenzinha para demonstrar seu deslocamento. Cédulas e moedas indicam que a pessoa está pensando em dinheiro, assim como corações indicam amor.

Com o mínimo de noção sobre todos os aspectos que envolvem a Nona Arte, um educador disponibilizará de um material rico que pode se transformar em subsídio para magníficas aulas de qualquer matéria em sala de aula.

Na próxima parte, veremos as adaptações de obras clássicas para este suporte e quais seus pontos positivos ou negativos.

\section{As adaptações do conto O Alienista, de Machado de Assis, para os quadrinhos}

\subsection{As adaptações de clássicos da literatura brasileira para os quadrinhos}

De acordo com Zeni (2007, p. 17) não há uma fórmula que garanta a qualidade de uma adaptação.

Antes de tudo, é preciso saber o que se pretende, pois uma adaptação pode ser auxiliar ao texto original, então é importante que ela seja a mais fiel possível ao texto original. Se seu objetivo é fazer uma releitura, a exigência será de que o autor utilize os recursos da nova linguagem tão bem quanto o autor do texto original.

É preciso uma preocupação muito grande com a qualidade, que a adaptação seja muito boa no seu novo meio, independente do original. Tanto que existem adaptações em diversos meios que ficam muito parecidas com os originais, mas tornam-se muito chatas.

Além da questão da mudança de meio e de linguagem, há também a técnica. Para o quadrinista Fábio Moon, que, junto ao irmão Gabriel Bá, adaptou para o formato o conto O Alienista, de Machado de Assis, uma das maiores preocupações na adaptação é o espaço que a revista tem para contar a história.

Explica Fábio, que também cita vantagens: 


\section{FACULDADE DE FORMAÇÃo dE PROFESSORES}

Quando se está escrevendo, o mundo que você cria está nas palavras e na imaginação do leitor, enquanto nos quadrinhos você tem que mostrar tudo aquilo. Se você tiver um número de páginas limitado, você terá que escolher melhor as imagens para caber tudo isso dentro da história.

Você pode trabalhar a imagem para traçar melhor o clima da história. Outra coisa é trabalhar melhor o silêncio; na parte escrita, quando um personagem faz silêncio, é preciso descrever isso. É quase como se estivesse acontecendo alguma coisa. Já nos quadrinhos, esses momentos silenciosos e de troca de olhares funcionam melhor.

Quando utiliza uma obra adaptada para os quadrinhos o leitor precisa ter consciência que a história nunca será contada de forma igual, pois a versão de uma obra já é a leitura do artista que a adaptou. É importante que o leitor tenha consciência de que esta lendo uma adaptação e não a própria obra literária, mesmo quando a adaptação mantém-se o mais fiel possível ao texto de base.

\section{2. $O$ capítulo $V$ nas quatro adaptações do conto $O$ Alienista, de Machado de Assis, em quadrinhos}

Durante muito tempo as HQs eram vistas como uma arte menor, já que lidavam com textos e imagens e não com o texto "original".

Vários livros clássicos da literatura brasileira e universal já foram adaptados para o público juvenil nas HQs. Como são suportes diferentes, o preconceito não se justifica, já tem como alvo um público diferente do leitor "tradicional". Algumas adaptações são mais fidedignas ao texto base, enquanto outras mais livres, como o caso das versões da Disney.

Veremos neste capitulo, a análise do capítulo cinco de quatro adaptações encontradas nas livrarias do conto $O$ Alienista, de Machado de Assis, para os quadrinhos, usando como base o texto de original.

$\mathrm{O}$ conto trata das fronteiras entre a sanidade e a loucura. Publicado no jornal carioca $A$ Estação, de 15 de outubro de 1881 a 15 de março de 1882, mas de forma definitiva na coletânea Papéis avulsos, em 1882.

A história se desenvolve mediante a chegada de um cientista em Itaguaí e de seus estudos sobre a loucura. Ele tenta determinar esses limites, classificando a loucura a partir dos critérios deterministas e positivistas, e não científicos propriamente ditos. 


\section{Abaixo segue a transcrição de um fragmento do texto original, encontrado no capítulo $\mathrm{V}$ do conto $O$ Alienista:}

\section{O TERROR}

Quatro dias depois, a população de Itaguaí ouviu consternada a notícia de que um certo Costa fora recolhido à Casa Verde.

- Impossível!

— Qual impossível! foi recolhido hoje de manhã.

- Mas, na verdade, ele não merecia... Ainda em cima! depois de tanto que ele fez...

Costa era um dos cidadãos mais estimados de Itaguaí. Herdara quatrocentos mil cruzados em boa moeda de el-rei D. João V, dinheiro cuja renda bastava, segundo lhe declarou o tio no testamento, para viver "até o fim do mundo". Tão depressa recolheu a herança, como entrou a dividi-la em empréstimos, sem usura, mil cruzados a um, dois mil a outro, trezentos a este, oitocentos àquele, a tal ponto que, no fim de cinco anos, estava sem nada. Se a miséria viesse de chofre, o pasmo de Itaguaí seria enorme; mas veio devagar; ele foi passando da opulência à abastança, da abastança à mediania, da mediania à pobreza, da pobreza à miséria, gradualmente. Ao cabo daqueles cinco anos, pessoas que levavam o chapéu ao chão, logo que ele assomava no fim da rua, agora batiam-lhe no ombro, com intimidade, davam-lhe piparotes no nariz, diziam-lhe pulhas. E o Costa sempre lhano, risonho. Nem se lhe dava de ver que os menos corteses eram justamente os que tinham ainda a dívida em aberto; ao contrário, parece que os agasalhava com maior prazer, e mais sublime resignação. Um dia, como um desses incuráveis devedores the atirasse uma chalaça grossa, e ele se risse dela, observou um desafeiçoado, com certa perfídia: - "Você suporta esse sujeito para ver se ele lhe paga". Costa não se deteve um minuto, foi ao devedor e perdoou-lhe a dívida.

- "Não admira, retorquiu o outro; o Costa abriu mão de uma estrela, que está no céu". Costa era perspicaz, entendeu que ele negava todo o merecimento ao ato, atribuindo-lhe a intenção de rejeitar o que não vinham meter-lhe na algibeira. Era também pundonoroso e inventivo; duas horas depois achou um meio de provar que lhe não cabia um tal labéu: pegou de algumas dobras, e mandou-as de empréstimo ao devedor.

"Agora espero que..." pensou ele sem concluir a frase.

Veremos a seguir como cada adaptação abordou o texto original. 


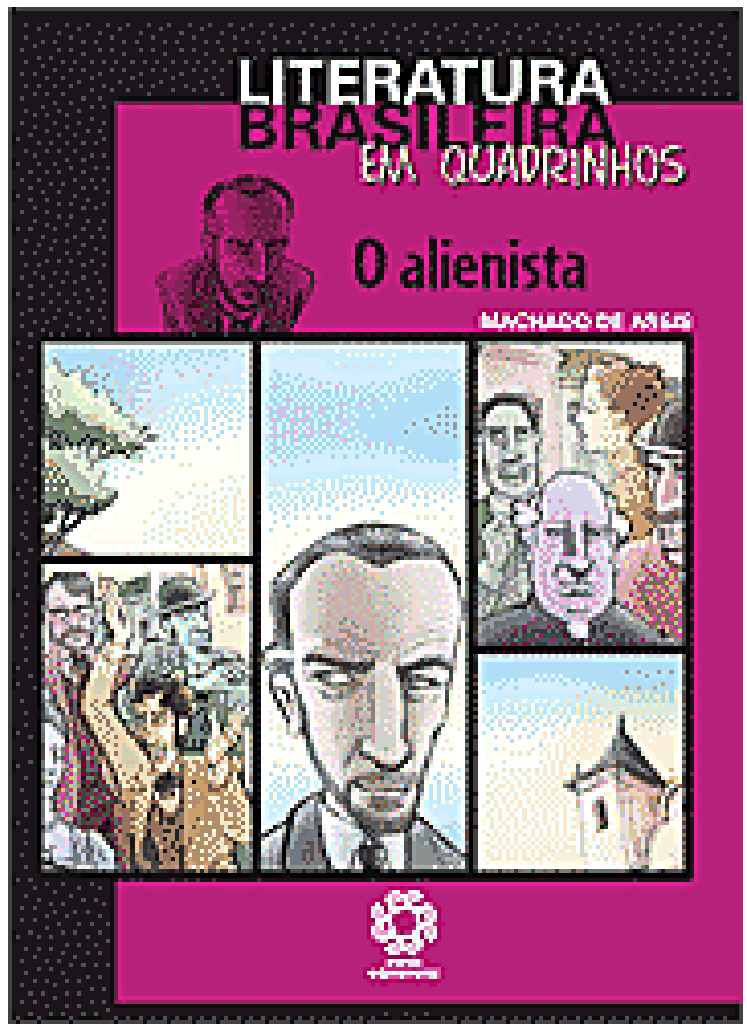

FIGURA 2 - Capa da adaptação que faz parte da coleção Literatura Brasileira Através de Quadrinhos (Escala Educacional)

Nesta adaptação que pertence à coleção Literatura Brasileira Através de Quadrinhos (Escala Educacional) foram usados poucos balões de diálogo e de pensamento, e houve uma exploração maior dos quadros narrativos.

A intenção das ilustrações é baseada nas feições dos personagens porem suas expressões faciais são pouco definidas, o que não valoriza a leitura visual. O cenário não acrescenta muito na construção do imaginário do leitor, pois não há riqueza de detalhes, mas o conteúdo do texto busca ser fiel ao original. 


\section{DEPARTAMENTO DE LETRAS}
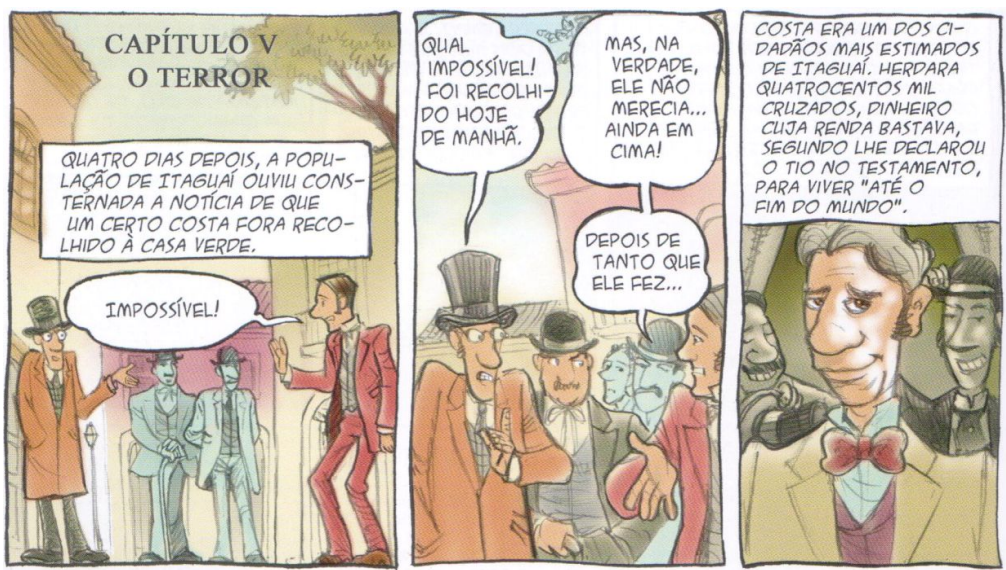

Figura 3 - Página 16 de $O$ Alienista

(Literatura Brasileira Através de Quadrinhos - Escala Educacional)

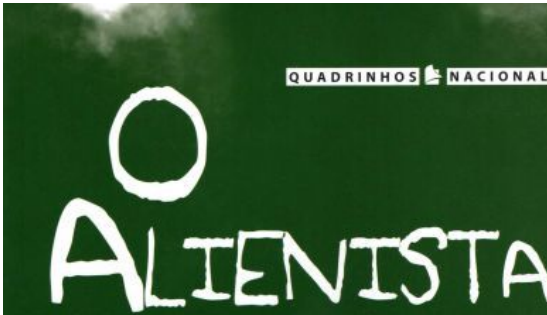

MACHADO DE ASSTS

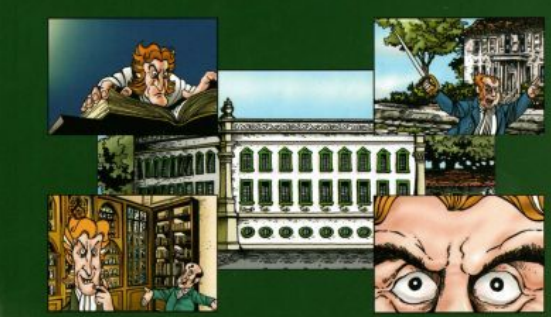

Adaptaçio de

Lailson de Holanda Cavalcanti

2

Figura 4 - Capa da adaptação que faz parte da Série Quadrinhos Nacionais (Companhia Editora Nacional) 


\section{FACULDADE DE FORMAÇÃO DE PROFESSORES}

As cores foram muito bem exploradas na adaptação da Companhia Editora Nacional. A ilustração do cenário demonstra a preocupação de facilitar o diálogo com o leitor tendo a finalidade de construir a imagem visual favorecendo sua interpretação. Há uma perfeita utilização dos balões de diálogo de fala e pensamento o que caracteriza que esta é uma boa adaptação. Há a preocupação do autor adaptador em identificar por meio de figuras e descrições. Na página 6 , os personagens principais que compõem a história. Porém, as personagens possuem traços gráficos caricatos, o que despertaria a atenção do público adolescente, não funcionando da mesma forma com o adulto. A adaptação mantêm a intenção da obra original.

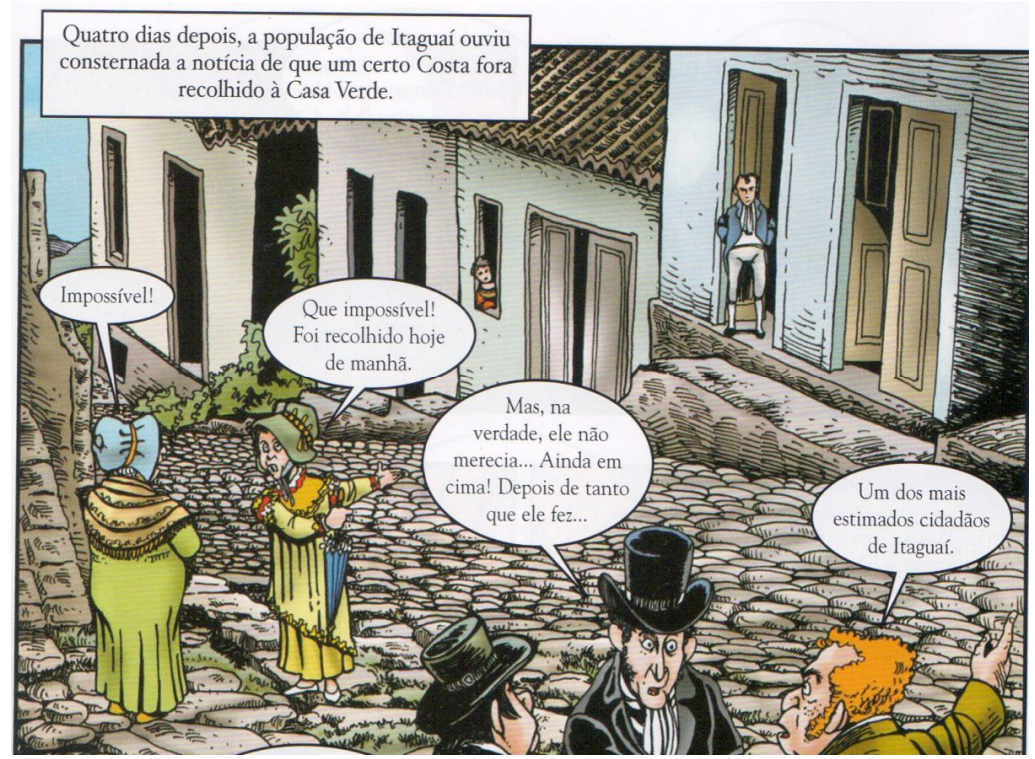

Figura 5 - Página 20 da adaptação de O Alienista, da Série Quadrinhos Nacionais (Companhia Editora Nacional) 


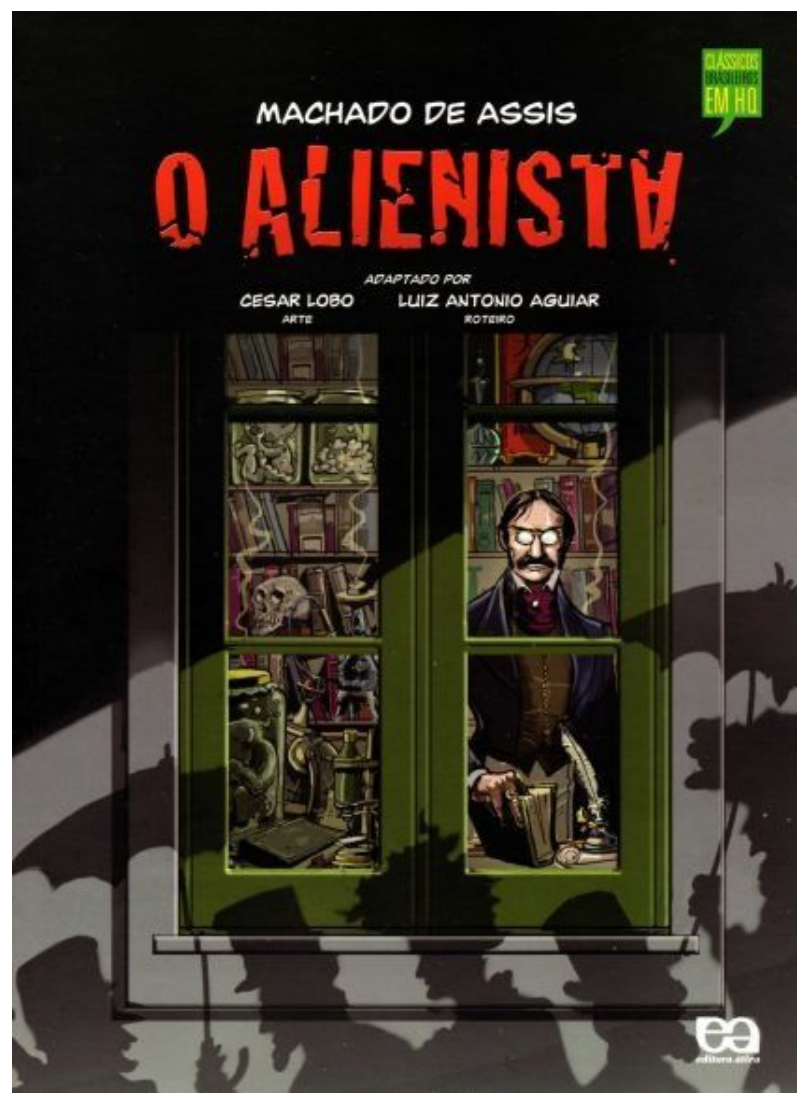

Figura 6 - Capa da adaptação que faz parte dos Clássicos Brasileiros em HQ (Ática)

Esta adaptação que faz parte dos Clássicos Brasileiros em HQ é muito bem ilustrada, e utiliza corretamente os balões de diálogo e pensamento, contém poucos balões narrativos o que a caracterizaria como uma boa adaptação, mas em meio a estas qualidades a invenção de um novo personagem a deixa extremamente longe da originalidade da obra de Machado de Assis. A intenção dos autores/adaptadores ao criarem a personagem "AA", era mostrar o lado negro de Bacamarte, personagem principal que não existe na obra original, pois seus atos eram impulsionados por suas crenças não havendo nenhuma intenção maléfica em seus julgamentos ou atitudes. 


\section{FACULDADE DE FORMAÇÃO DE PROFESSORES}

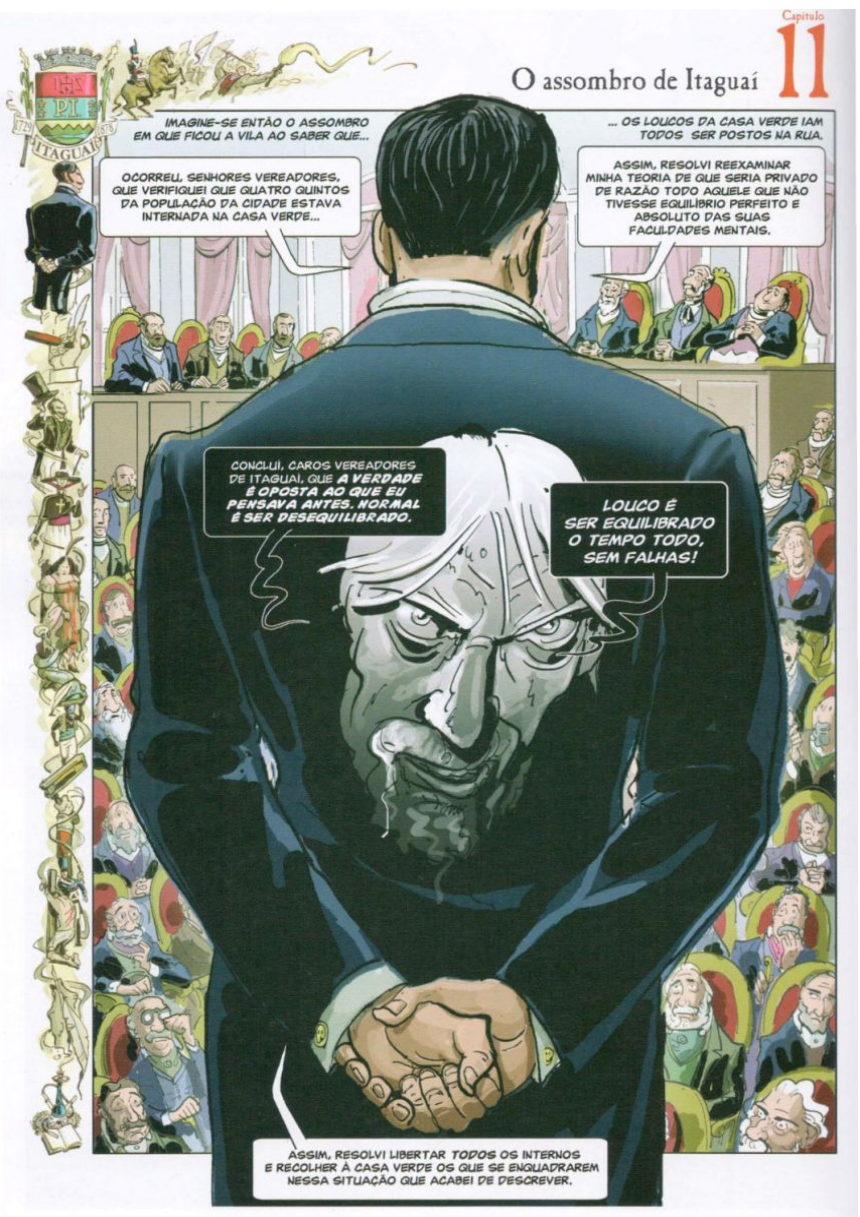

Figura 8 - Página 58 da adaptação de O Alienista, Clássicos Brasileiros em HQ (Ática)

A resposta à criação do personagem AA pode ser encontrada abaixo:

A personagem AA, foi uma criação dos autores para melhor interpretar o espírito que entendiam haver na história e no personagem Simão Bacamarte, ele enfatiza algumas falas do médico e ás vezes a completa. É um duplo se Simão Bacamarte, o Outro Oculto do alienista. (Cesar Lobo e Luiz Antonio Aguiar, 2007) 


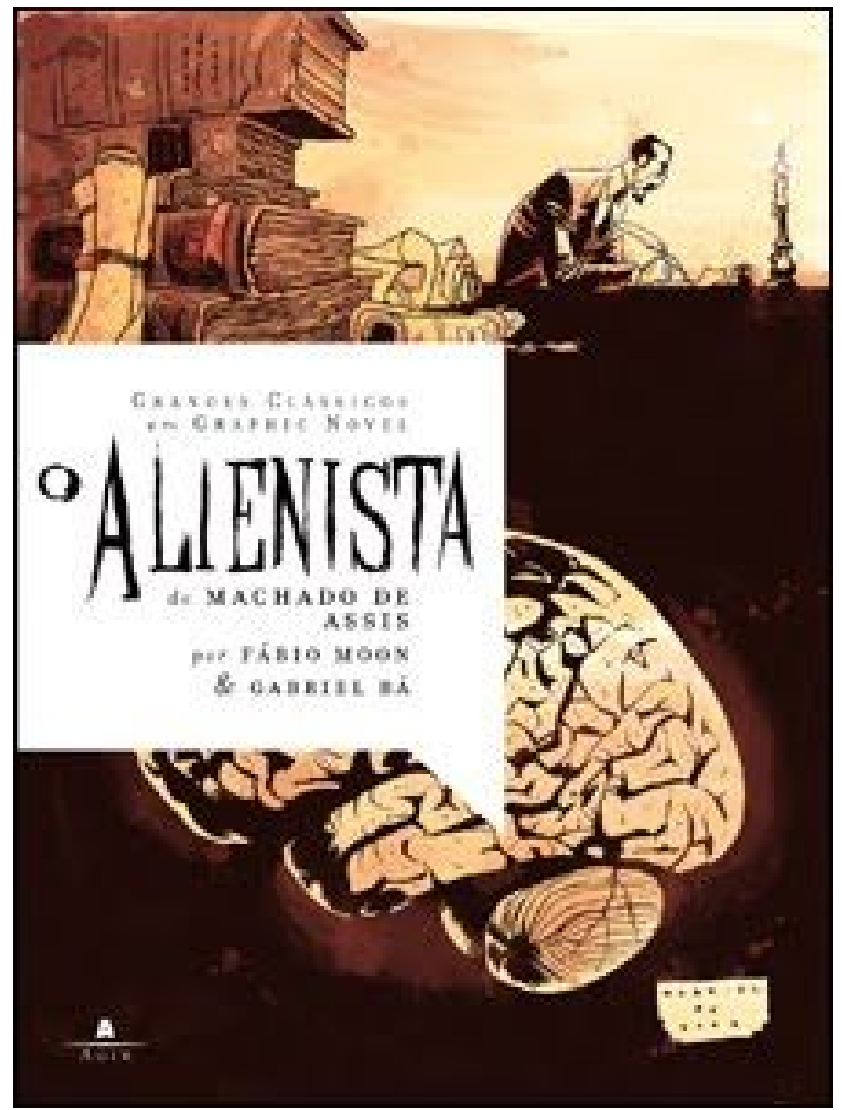

Figura 9 -

Capa da adaptação que faz parte dos Grandes Clássicos em Graphic Novel (Agir)

A adaptação da Agir é um graphic novel. Logo é voltada para o público adulto. A originalidade da obra clássica é mantida pelos adaptadores. $\mathrm{O}$ cenário bem desenhado contribui para a construção visual do leitor, as cores são em tons pasteis, não interferindo na interpretação do texto visual. Os balões de diálogo e pensamento são muito bem utilizados. Como grande parte do texto. O Alienista é composto por narrativas, os diálogos são pouco definidos, o que dificulta a originalidade, nas adaptações para a nona arte que é composta basicamente por diálogo. Embora a adaptação já seja a transcrição da interpretação do autor adaptador, os autores Fábio Moon e Gabriel Bá conseguiram fazer desta adaptação a mais fiel das adaptações analisadas neste trabalho. 

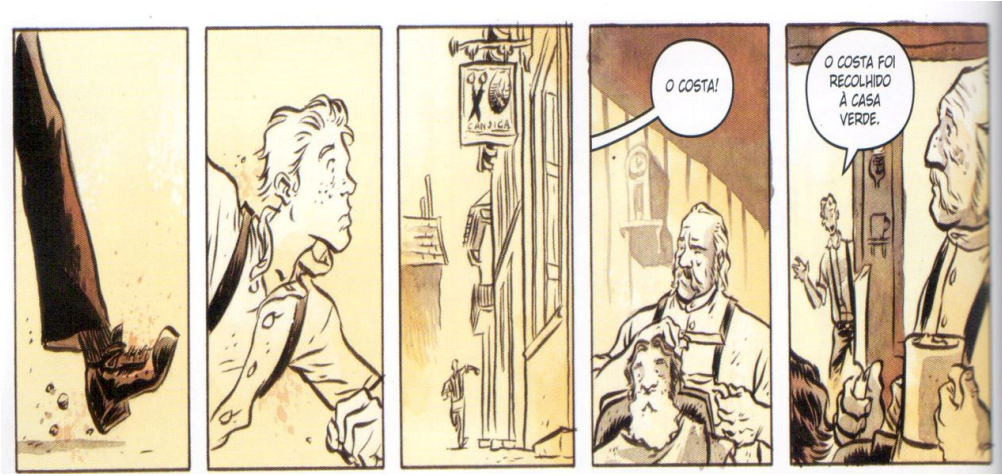

Figura 10 - Página 24 da adaptação de O Alienista dos Grandes Clássicos em Graphic Novel (Agir)

$\mathrm{Na}$ próxima parte apresentaremos as possibilidades da utilização dos quadrinhos como instrumento para estimular a leitura de clássicos pelos estudantes do ensino fundamental e médio.

\section{A utilização dos quadrinhos nas atividades pedagógicas nas ativi- dades pedagógicas em sala de aula}

Como já foi dito no primeiro capítulo a utilização dos quadrinhos já sofreram preconceitos, mas hoje, os tempos são outros. Os Referenciais Curriculares Nacionais para a Educação Infantil (RCNEI), e os Parâmetros Curriculares Nacionais (PCN) já os contemplam e destacam sua importância ao sugerir o trabalho com diversas mídias em sala de aula. Em 2007, dez anos depois da criação do Programa Nacional Biblioteca na Escola (PNBE), as histórias em quadrinhos (HQs) finalmente foram incluídas nos acervos distribuídos a bibliotecas escolares. Foram 14 livros naquela edição e outros 16 em 2008. Em 2009, as HQs já representam 4,2\% dos 540 títulos listados pelo programa. Disponível em: <http://www.educacaopublica.rj.gov.br/suavoz/0116.html>. Acesso em: $01 / 06 / 2011$

Entre os motivos para utilizar os quadrinhos na escola, estão à atração dos estudantes por esse tipo de leitura, a conjunção de palavras e imagens, que representa uma forma mais eficiente de ensino, o alto nível de informação deles, o enriquecimento da comunicação pelas histórias em quadrinhos, o auxílio no desenvolvimento do hábito de leitura e a ampliação do vocabulário. O que se vê cada vez mais é a formalização 
desse gênero textual na sala de aula, mas muitos professores ainda têm dúvidas sobre como utilizá-lo. Que aspectos devem ser explorados. Os quadrinhos podem ser utilizados em qualquer disciplina

A proposta da utilização dos quadrinhos pelos professores em atividades pedagógicas é positiva e seria útil nos estabelecimentos de ensino fundamental, médio e até em universidades, pois sua leitura também pode levar à reflexão e ao autoconhecimento.

Diz Elydio Fonte:

A leitura dos quadrinhos favorece um desenvolvimento mais harmonioso entre as tarefas de analisar racionalmente e o trabalho de ler o mundo com sensibilidade. Quero lembrar também que o próprio Ministério da Educação sugere a utilização das histórias em quadrinhos no trabalho escolar.

Se o professor buscar "pedagogização" das histórias em quadrinhos, promoverá uma utilização empobrecida das mesmas, uma vez que se deixa de explorar todo o potencial artístico e comunicacional que esta linguagem tem e que merece ser explorada por si mesma.

\subsection{Incentivo à leitura}

O desinteresse pela leitura por parte das novas gerações tem sido explicado, de forma generalizada e até mesmo preconceituosa, como consequência dos meios visuais e audiovisuais. Acredita-se que a aversão pelos textos seja provocada pela televisão e, mais recentemente, ao videogame e à Internet. E nem mesmo a história em quadrinhos deixa de ser mencionada nas críticas de teóricos e educadores que procuram entender as causas da rejeição à palavra escrita (e impressa) por parte dos jovens.

Outro fator que recebe também o peso de contribuir com a falta de interesse pela leitura é o poder aquisitivo da população que não permiti a compra frequente de livros, o que não é justificado pois há também a falta de interesse pela leitura no caso de estudantes vindos de extratos mais altos da sociedade, que têm poder aquisitivo e podem frequentar escolas particulares pagas.

O fato de o hábito de leitura ter diminuído nas últimas décadas pode ser creditado a um fator cultural: o brasileiro não está sendo instigado a ler, ou por causa da censura nos anos 70 , ou devido à falta de incentivo por parte das escolas e dos pais, pelo número reduzido de bibliotecas etc. 
Mas o professor pode mudar este fato através da utilização dos quadrinhos nas atividades pedagógicas dos alunos.

O preconceito existente contra os quadrinhos por parte de pais e educadores fecha a possibilidade de utilizar este veículo de comunicação para incentivar a leitura. A criança que não lê história em quadrinhos tampouco se sentirá disposta a enfrentar textos didáticos, literários e informativos. A utilização de quadrinhos pode ser de grande valia para iniciar o jovem no caminho que leva à consolidação do hábito e do prazer de ler.

As histórias em quadrinhos facilitam as crianças em seu crescimento mental, por este motivo as agradam tanto.

Azis Abrahão considera que a história em quadrinhos, denominada por ele "literatura em quadrinhos", agrada às crianças uma vez que atende a sua necessidade de crescimento mental. Na sua opinião, as crianças

pouco entendem da literatura produzida para elas. $\mathrm{O}$ desinteresse que nutrem, por qualquer gênero de leitura, que não seja de quadrinhos, pode ser explicado pela falta de familiarização com certas noções abstratas da linguagem comum, particularmente da linguagem escrita, pela dificuldade experimentada na análise de seu vocabulário e do sistema de imagens e ideias, pelo defeituoso aprendizado da leitura, pela limitação de seus quadros e experiências etc. (MOYA, 1977, p. 149-150).

Assim, a história em quadrinhos, ao falar diretamente ao imaginário da criança, preenche suas expectativas e a prepara para a leitura de obras escritas. A experiência de folhear as páginas de uma revista de quadrinhos pode gerar e perpetuar o gosto pelo livro impresso, independente de seu conteúdo. Além disso, o aprendizado por meio do uso de quadrinhos, como será visto a seguir, é mais proveitoso.

\subsection{Utilizações dos quadrinhos em livros didáticos}

Há três décadas, os quadrinhos vêm sendo utilizados com sucesso em livros didáticos.. A união de artistas e pedagogos tem sido muito importante para o aproveitamento das possibilidades técnicas, narrativas e expressivas dos quadrinhos para uma divulgação mais eficiente de conhecimento.

No entanto, Sonia Bibe Luyten observa que, pelo caráter comercial de muitos livros didáticos, ocorrem distorções, os erros mais comuns 
nas obras didáticas que utilizam HQs são: quadrinhos com excesso de texto e imagens muito chamativas em detrimento do conteúdo.

"Há livros que, apenas para vender mais, inserem alguns elementos de quadrinhos (balões ou onomatopeias) em velhas imagens conhecidas". Pondera, ainda, a respeito de a disciplina ser afeita ou não à quadrinização: em matérias das Ciências Humanas (Geografia, História, Sociologia), "quando a quadrinização é mal feita, a imagem pode transmitir figuras deturpadas, gerar estereótipos, conotações ideológicas, ou seja, interpretações errôneas dos acontecimentos". (BIBE LUYTEN, 1984, p. 88-89),

Contudo, a linguagem característica dos quadrinhos e os elementos de sua semântica, quando bem utilizados, podem ser aliados do ensino. A união de texto e desenho consegue tornar mais claros, para a criança, conceitos que continuariam abstratos se confinados unicamente à palavra. Na visão de Azis Abrahão, texto e ilustração

se ajustam e se testam na identificação de seus significados e de suas relações, naquela necessária integração de matéria e forma, que tão bem atende aos princípios atuais da Pedagogia, baseados no caráter sincrético e globalizador do pensamento da criança (MOYA, 1977, p. 143).

Portanto, o aluno é estimulado a interpretar a história em quadrinho, desde a maneira com que se articula a narrativa quadrinhográfica focando a sequencialidade, com uma vinheta sucedendo a outra, em ordem lógica, mas fragmentada temporalmente, pois esta organização textual exige a participação e perspicácia da parte do leitor para preencher os momentos não mostrados isto é uma forma de provar que a arte sequencial não deixa o aluno menos criativo por ter imagens visuais e sim o incentiva a pensar e reagir aos estímulos feitos através dos quadrinhos.

O caráter de verdadeiro relato visual ou imagístico, que sugestivamente se integra com as rápidas conotações do texto escrito, numa perfeita identificação e entrosamento das duas formas de linguagem: a palavra e o desenho. Exatamente como convém ao caráter sincrético e intuitivo do pensamento infantil (MOYA, 1977, p. 150-151).

Dessa forma, o quadrinho torna mais interessante o conteúdo a ser estudado, e exige do aluno uma percepção maior do meio empregado, a história em quadrinhos.

Para justificar as afirmações acima. Veremos algumas formas da utilização dos quadrinhos como recursos materiais para as aulas de português. 


\subsection{Os quadrinhos nas aulas de português e literatura}

Uma forma adequada da utilização dos quadrinhos nas aulas de português é fazer um trabalho conjunto com o conteúdo programático desta matéria e os recursos encontrados nos quadrinhos. Por exemplo, o professor sugere a leitura do livro $O$ Alienista, de Machado de Assis, comenta com a sala e depois mostra como aquilo foi retratado nos quadrinhos, fazendo um estudo comparativo,buscando através dos recursos da arte sequencial as interpretações visuais que na obra clássica só se construíram mentalmente, pois a leitura dos quadrinhos favorece um desenvolvimento mais harmonioso entre as tarefas de analisar racionalmente e o trabalho de ler o mundo com sensibilidade.

Outra forma de utilizar os quadrinhos com os alunos é trabalhar a imagem para traçar melhor o clima da história, como por exemplo, trabalhar melhor o silêncio; na parte escrita, quando um personagem faz silêncio, é preciso descrever isso. É quase como se estivesse acontecendo alguma coisa. Já nos quadrinhos, esses momentos silenciosos e de troca de olhares o que para o leitor funciona melhor. Fazer o aluno perceber esta diferença favorece a capacidade de leitura visual do mesmo, pois o professor estará trabalhando a meta linguagem e a intertextualidade da obra.

Podemos trabalhar também, estimulando os alunos a preencherem os balões dos quadrinhos que o professor apresentará, desta forma ele poderá explorar as metáforas visuais, a coesão dos textos produzidos pelos alunos, a leitura crítica e a interpretação de texto.

Estas e outras atividades poderão ser enriquecidas pelo professor quando o mesmo lança mão de um recurso extremamente abrangente como é a historia em quadrinho.

\section{Conclusão}

O emprego da história em quadrinhos no processo de aprendizado é, portanto, um meio muito rico para os educadores. Como foi observado ao longo deste trabalho, são várias as possibilidades encontradas nos quadrinhos que podem ser aplicadas no processo educativo, com o intuito de transmitir conhecimentos, despertar o interesse e criar o hábito da leitura sistemática, conscientizar, fomentar atitudes críticas, desenvolver a aptidão artística e a criatividade dos alunos. 
Conhecer e identificar os elementos que compõem a linguagem característica dos quadrinhos e também estão presentes em sua narrativa auxiliam a análise desta forma de comunicação que também é uma manifestação artística e uma ferramenta pedagógica. Proceder à análise de histórias em quadrinhos coletivamente, em sala de aula, além de ser um exercício prazeroso e instigante, também aguça o espírito crítico de alunos e professores.

Basta apenas que educadores e pais percam o preconceito ainda existente em relação à História em quadrinhos e passem a considerar este meio de expressão artística como forte aliado na formação dos jovens.

\section{REFERÊNCIAS BIBLIOGRÁFICAS}

ASSIS, Machado de Assis. O alienista. Roteiro, desenhos Francisco S. Vilachã; cores Fernando A. A. Rodrigues, Série literatura brasileira em quadrinhos. São Paulo: Escala Educacional, 2006.

ASSIS, Machado de. $O$ alienista. Adaptação de Fábio Moon e Gabriel Bá: apresentação de Flávio Moreira Costa. Rio de Janeiro: Agir, 2007.

ASSIS, Machado de. O alienista. Adaptação, roteiro e desenhos de Lailson de Holanda Cavalcanti. São Paulo: Cia. Ed. Nacional, 2008.

ASSIS, Machado de. O alienista. Adaptado por Cesar Lobo, arte; Luiz Antonio Aguiar, roteiro. São Paulo: Ática, 2008.

ASSIS, Machado de. O alienista. São Paulo: Nobel, 2010.

BIBE LUYTEN, Sonia M. O que é História em quadrinhos. São Paulo: Brasiliense (Coleção Primeiros Passos, 144), 1985.

GOTLIEB, Liana. Mafalda vai à escola: a comunicação dialógica de Buber e Moreno na Educação, nas tiras de Quino. São Paulo: Iglu/CCAECA-USP, 1996.

MOYA, Álvaro de. Shazam! 3 ed. São Paulo: Perspectiva (Debates, 26), 1977

RAMA, Ângela e VERGUEIRO, Waldomiro(orgs). Como usar história em quadrinhos em sala de aula. São Paulo: Contexto, 2004. 